\title{
DEVELOPMENT OF RIVPACS IN THE UK AND THE VALUE OF THE UNDERLYING DATA-BASE
}

\author{
John F. Wright \\ Institute of Freshwater Ecology. River Laboratory. \\ East Stoke, Wareham, Dorset, BH20 6BB ENGLAND
}

\section{INTRODUCTION}

RIVPACS stands for River Invertebrate Prediction And Classification $\underline{S} y s t e m$, a technique developed by the Institute of Freshwater Ecology (IFE) for evaluating the biological quality of rivers. The project which eventually lead to RIVPACS started in October 1977, when a small group of invertebrate zoologists were brought together to develop more sophisticated approaches to the detection of pollution and environmental stress using biological information.

Chemical assessments of water quality have always been an essential element in the protection of rivers, particularly when water is required for human consumption. But chemical monitoring alone tells us little of the effects of pollution, which is essentially a biological phenomenon in so far as its effects are on living organisms.

During the 1970's an increasing number of biologists were employed within the Water Industry in Great Britain to help in the detection of water pollution. They favoured the use of benthic macroinvertebrates for biological assessments because their taxonomy was well known and a wide range of species occurred throughout most freshwater habitats (HELLAWELL, 1986). The relatively sedentary habits and length of life cycle of many species meant that they had the potential to integrate and respond to a range of different environmental stresses. Intermittent pollution might be missed by periodic chemical monitoring, as would pollutants in very low concentrations, or those not tested for, but the assemblage of macroinvertebrates on the river bed was a permanent monitor within the river itself, with no ready means of escaping detrimental impacts.

Therefore, over a period of time, it was recognised that both chemical and biological approaches were important and should be viewed as complementary rather than alternative techniques.
In the late 1970's biologists employed within the Water Industry focused much of their attention on the detection of organic pollution. Typically, this was reported to managers using the Trent Biotic Index (WOODIWISS, 1964) or Chandler score (CHANDLER, 1970). Although these approaches were effective at identifying badly polluted sections of river which required immediate attention, they took no account of the macroinvertebrates to be expected at the site in the absence of major environmental stress. Clearly, the fauna will vary according to the physical and chemical characteristics of the site and the location of the site along the length of the water course. This is the essence of the problem. For the biological approach based on the structure of the invertebrate assemblage to be realistic and flexible, a procedure is required for determining the macroinvertebrates to be expected at any given site in the absence of environmental stress. Only then do you have a basis on which to judge whether the fauna you observe is what you expect, or whether the assemblage has changed in response to a pollutant or other form of environmental stress.

The research project which began at the River Laboratory in 1977 was funded jointly by the Natural Environment Research Council and the Department of the Environment, acting on behalf of the Water Industry. Initially the research was supported for a period of 4 years and two objectives were set. These were (i) to develop a biological classification of unpolluted running-water sites based on the macro-invertebrate fauna and (ii) to determine whether the fauna to be expected at an unstressed site could be predicted from physical and chemical features only. A classification would be of particular value and interest to those with responsibilities in the field of nature conservation, but in practice, the classification was also required for developing the prediction system. Prediction was the major challenge for the research team, because this approach had not previously been attempted. 
However, we had a number of advantages, including the active cooperation of biologists and their managers within the Water Authorities of England and Wales and the River Purification Boards in Scotland. In addition the macroinvertebrate fauna of Great Britain is well docurnented with taxonomic keys and good quality physical and chemical data are readily available for a wide range of sites throughout the country. We also had within the team a statistician who was familiar with recent developments in the field of rnultivariate statistics.

Funding for the progressive development of our approach has continued under the sponsorship of a series of organisations ever since and a number of publications describing the methodologies employed and the application of RIVPACS will be referred to later. One recent publication (WRIGHT et $a l ., 1993$ a) provides an up to date account of the development of the system which the reader can consult for details. Within this paper my priorities are to offer a succinct, self-contained account of the development of RIVPACS, a demonstration of the current uses of the system, the additional value of the data-set on which it is based and finally a brief view of future developments.

\section{THE BIOLOGICAL AND ENVIRONMENTAL DATA-SET}

The rationale for choosing sites, the procedures for field sarnpling and laboratory identification, together with the methods employed to obtain the physical and chemical data are all detailed in WRIGHT et al. (1984) and only a brief synopsis will be given here.

Great Britain is a heavily populated island with a legacy of problerns in some industrialised areas, but despite this, a relatively small proportion of the rivers are badly polluted (NATIONAL WATER COUNCIL, 1981; DEPARTMENT OF THE ENVIRONMENT AND THE WELSH OFFICE, 1986; ARMITAGE et al., 1992). Although no river in Britain can be regarded as pristine it was possible, after consultation with Water Industry biologists, to choose a series of high quality sites throughout the country for use in developing a practical system capable of setting high standards.

By 1981, a prototype system was in place based on 268 sites from 41 river systems. This was extended to 370 sites on 61 rivers by 1984 and then to 438 sites on almost 80 systerns by 1988 (Fig. 1).

The location of sites within each river was chosen with care in order to reflect the fact that changes in species composition are greater near the source than further downstream (VERNEAUX, 1976). Typically, suitable locations were approximately 5, 10, 20, 30, 40 and thereafter at $20 \mathrm{~km}$ intervals downstream.

To ensure that the classification was based on an adequate representation of the macroinvertebrate fauna of each site, sampling was undertaken in each of spring, summer and autumn. With few exceptions, a standard FBA pond-net was used and during a 3-minute timed coIlection, all the major habitat types were sampled, approximately in proportion to their occurrence. At large deep sites where pond-netting alone was inadequate, use of a light weight dredge coupled with pond-netting of marginal areas became the preferred option.

In the initial stages of the project, all field sampling was carried out by Water Industry staff, following detailed guidelines prepared by the research team. Later on, the work load was shared with members of the research team. However, all the sample sorting and identifications were carried out by staff at the River Laboratory. Species identifications were rnade where adequate keys were available. The data used for site classification comprised a single list of the macroinvertebrate fauna recorded after combining the results from three seasons sampling and after the application of standard protocols to remove duplicate higher taxa and ensure that inter-site comparisons were valid. A list of 60-90 taxa was typical of many sites but in excess of 120 taxa were found at a few species-rich sites.

Twenty-eight environmental variables were used in the initial analyses based on 268 sites (WRIGHT et al., 1984). These included site physical attributes and macrophyte data recorded on site, additional physical data obtained from maps and chemical data provided by Water Industry staff. As the data-base was expanded, new site attributes were acquired from other sources and some of the original features recorded on site were eliminated from the analyses

\section{CLASSIFICATION AND PREDICTION TECHNIQUES}

We chose TWINSPAN (HILL, 1979), a polythetic divisive technique for the classification of sites based on their faunal composition. The technique had been compared favourably with alternative hierarchical classification techniques (GAUCH \& WHITTAKER, 1981), it was computationally efficient and offered a simple 'key' based on differential species whereby a new site could be classified without the need to reclassify all sites. When TWINSPAN 


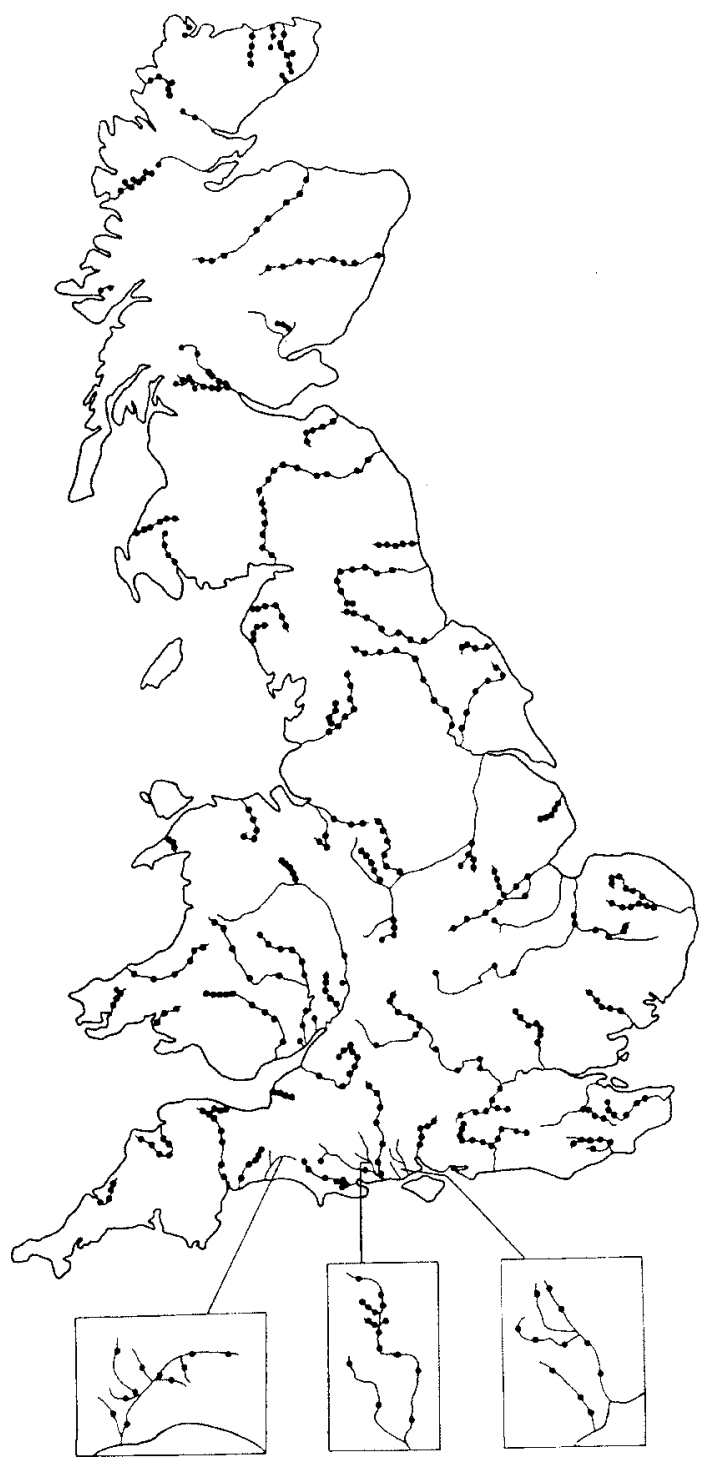

FIGURE 1. The 438 sites used in RIVPACS II

was used on the 268 site data-set we generated 16 classification groups (WRIGHT et al., 1984). The same procedure was used later on for classifying the 370 sites (30 groups) and the 438 site data-set ( 25 groups).

Sites within a given classification group can be expected to have relatively similar macroinvertebrate assemblages, which can be distinguished from those in other groups. The next step was to determine the extent to which sites within any given group had similar environmental features which distinguished them from all other groups. This was investigated using multiple discriminant analysis (MDA) (KLECKA, 1975).
The procedure starts with the 16 classification groups already defined by their biological attributes (benthic fauna) and then seeks combinations of the 28 environmental variables which are most effective at predicting the 16 classification groups. It involves ordinating the sites using the environmental data in order to maximize the separation of sites in different classification groups but minimizing the separation of sites within each group.

A simple demonstration of the principle of the technique is shown in Fig. 2. This illustrates the way in which a new ordination axis (discriminant function) allows two site groups to be discriminated using just two environmental variables. In practice, many more environmental variables are available in order to differentiate between site groups. In addition, a number of ordination axes (discriminant functions) are required to separate 16 groups in discriminant space. Each discriminant function is defined by an equation in which field values of environmental variables are multiplied by individual weighting factors and these, together with a constant, are summed to provide a discriminant function score. The discriminant functions share the same variables but each one uses different weighting factors and constants.

The environmental attributes recorded for each of the 268 sites, when used in the discriminant function equations, can demonstrate the strength of the match between the biological features of the sites and their environmental features. In theory, a given site could be placed into any one of the 16 classification groups on the basis of its environmental attributes. In reality, the result is expressed as a series of probabilities (totalling 100\%) that the site would occur in each of the 16 groups. Only when the site is predicted with the highest probability to the same group into which it was originally classified using the macroinvertebrate data is the prediction taken as correct. Using this 'internal' test $76.1 \%$ of the 268 sites were predicted to the correct classification group and a further $15.3 \%$ were near misses (WRIGHT et al., 1984).

This strong evidence of the linkage between the environmental features of good quality sites and their macroinvertebrate assemblages, meant that the environmental features of a new unsampled site could be used in the equations to predict the probabilities of classification group membership, and hence the fauna, of the site.

The transition from prediction of classification group(s) to prediction of the component taxa at the site was the novel step in our approach and was achieved as follows. Imagine a classification group with 20 sites. Since they were 


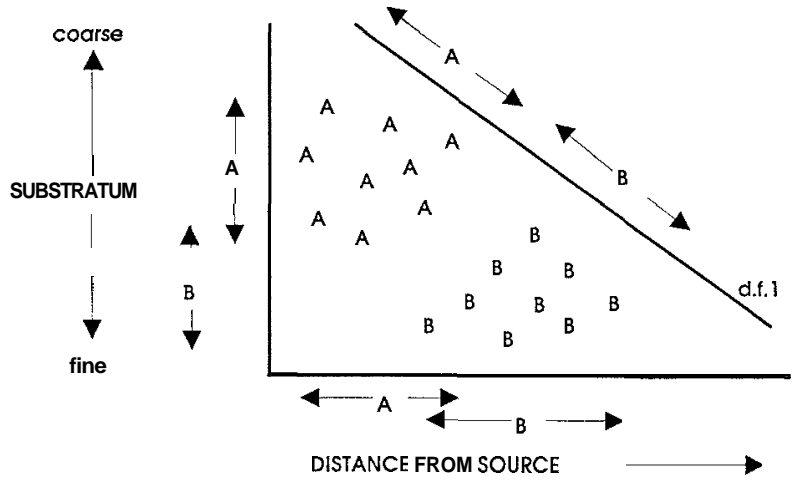

FIGURE 2. A demonstration of the principle of multiple discriminant analysis based on two groups of sites (A, B), two environmental variables and one discriminant function (d.f.1)

brought together as a group they will have many taxa in common and it is a simple matter to determine the percentage of sites within the group at which each taxon occurs. These percentages are regarded as analogous to the probabilities of the taxa being recorded at a site if it is subjected to the standard RIVPACS sampling procedures and is free from environmental stress. Thus one taxon might be present at all 20 sites (100\% frequency of occurrence), another at 15 sites $(75 \%)$, others at 10 sites $(50 \%)$ and so on. If a new site had been predicted to that single classification group with a $100 \%$ probability, then the $\%$ frequency values for the component taxa would become the \% probabilities of occurrence of the 'target' invertebrate assemblage to be expected at the site, for comparison with the actual fauna present. The procedure for comparing the target assemblage, expressed as \% probabilities of capture for each taxon with the observed fauna which has taxa either present or absent is as follows. You would expect to find all taxa predicted with $100 \%$ probability, approximately 3 out of 4 predicted with $75 \%$ probabilities, 1 out of 2 at $50 \%$ and so on if the site was of good quality (WRIGHT et al., 1988). A detailed prediction follows in a later section.

In a typical case where a new site is predicted to a series of classification groups with different probabilities instead of one group with $100 \%$ probability, the calculation of the probability of capture of, say, taxon $\mathrm{X}$ is as follows.

$\begin{array}{cccc}\begin{array}{c}\text { Classification } \\ \text { group }\end{array} & \begin{array}{c}\text { Probability that new } \\ \text { site belongs to group }\end{array} & \begin{array}{r}\text { Frequency of taxon } \\ \mathrm{X} \text { in group }\end{array} & \begin{array}{r}\text { Contrihution to the } \\ \text { probab. that taxon } \\ \mathrm{X} \text { will occur }\end{array} \\ \text { A } & 0.80 & 75 \% & 60 \% \\ \text { B } & 0.15 & 60 \% & 9 \% \\ \text { C } & 0.05 & 20 \% & 1 \%\end{array}$

Combined probability that taxon $\mathrm{X}$ will occur $=70 \%$

A more detailed mathematical treatment of the procedure is given in MOSS et al. (1987).

\section{DEVELOPMENT OF RIVPACS}

\section{a) RIVPACS I}

With the basis of a prediction technique in place, the next phase was to develop the first version of the system for widespread assessment within the Water Industry. This was undertaken using the more comprehensive 370 site data-set (30 classification groups) which became available in 1984. Attention was also focused on the use of new environmental features in an attempt to increase predictive capability. The latitude and longitude of each site were recorded and measures of mean air temperature and air temperature range were also acquired as the best available surrogate measures of stream temperature.

The new classification, with a larger number of site groups, coupled with the use of further environmental variables meant that the MDA had to be repeated to obtain new predictive equations. These demonstrated the value of the new environmental features for prediction but also brought into focus the question of redundancy in the list of variables. Clearly, a practical system must avoid the time-consuming task of collecting a large block of environmental data for a site which then gives little or no benefit compared to a few select environmental variables. Early indictions (MOSS et al., 1987) were that a relatively small group of environmental attributes could be used with little loss of predictive capability. Therefore, in devising the first version of the system for testing (RIVPACS 1), four sets of variables were offered for appraisal (Table 1).

At this time both the classification and prediction system operated at species level only, so it was necessary to undertake some developments particularly on the prediction side to enable the system to have more widespread value to Water Industry biologists in routine monitoring. In particular, this meant incorporating predictions based on the Biological Monitoring Working Party (BMWP) system (NATIONAL WATER COUNCIL, 1981) which had been devised for, and first used in, the 1980 River Quality Survey in Great Britain.

The BMWP system, which uses selected family level (presence/absence) data was devised for rapid site assessment and involves allocation of scores in the range 1-10 to 
TABLE 1. The four environmental options available for prediction in RIVPACS I

\begin{tabular}{lll}
\hline$N^{\circ}$ variables & Physical and Chemical & Physical only \\
\hline 5 only & Distance from source & Distance from source \\
& Mean substratum & Mean substratum \\
& Total oxidised nitrogen & Altitude \\
& Total alkalinity & Mean air temperature \\
& Chloride & Air temperature range \\
\hline \multirow{2}{*}{ (ie the 5 above plus) } & Slope & Slope \\
& Altitude & Discharge category \\
& Mean water width & Mean water width \\
& Mean water depth & Mean water depth \\
& Mean air temperature & Latitude \\
& Air temperature range & Longitude \\
\hline
\end{tabular}

selected 'families' of macroinvertebrates according to their known tolerance to organic pollution. The most pollution sensitive families score 10 , whilst more tolerant families score progressively lower numbers until you reach Chironomidae (score 2) and finally Oligochaeta (1). The BMWP score for a given site is obtained by adding the individual scores of the component families present. Because the scoring system was devised in relation to organic pollution, the Average Score Per Taxon (ASPT), that is total BMWP score divided by the number of scoring families is often a useful index for site appraisal (ARMITAGE et al., 1983).

Modification of the prediction system to accommodate the BMWP system was achieved by downgrading species predictions to BMWP family level and then undertaking internal calculations to generate predicted BMWP score, number of taxa and ASPT. Alternative scoring systems could also be accommodated if required.

By 1985 , the BBC B microcomputer was widely available in Great Britain and the decision was taken to develop RIVPACS I software for use on this machine to ensure that it could be subjected to extensive testing within the Water Industry. Later that year a series of demonstrations of the BBC B version of the system were given to Water Authority (WA) and River Purification Board (RPB) biologists throughout Great Britain to explain the capabilities and operation of the system. Copies of the software, together with a practical manual which covered field and laboratory procedures in addition to a step-by-step account of the operation of the software, were then made available to each WA and RPB in March 1986.
New sites could be classified to a group by using the TWINSPAN key and interactively answering a series of questions on the taxa present at the site of interest. Similarly, predictions were available by inputting environmental data (4 options) for a site and selecting the taxonomic level(s) at which predictions were required. Site classifications were only possible after sampling in spring, summer and autumn and similarly, all predictions were of the fauna to be expected at an unstressed site after sampling in three seasons using standard RIVPACS procedures.

A questionnaire on RIVPACS I completed by most WA/RPB regions indicated that the prediction system was regarded as the most useful feature and $85 \%$ thought that they would use it in their routine work in future. The Water Industry biologists also offered some useful criticisms and suggestions for refining and improving the system and these, coupled with our own tests on the relative merits of the four sets of environmental options provided a good basis for developing the next version.

\section{b) RIVPACS II}

RIVPACS II, the current version of the system, represents a substantial step forward with respect to operational efficiency, flexibility of the prediction system and provision of results in a form which biologists and managers alike can use for decision-making. This has been possible through a combination of advances and additions to RIVPACS itself, and because the system has been adapted for use on IBM and IBM-compatible personal computers.

RIVPACS II is based on a slightly enlarged 438 site da 
ta-set which encompasses a wider range of river types, but classifies them into just 25 groups, ranging from 6 to 36 sites per group. Again, MDA was used on different combinations of environmental features to generate new equations for prediction of target communities. Initially, a single set of 11 easily acquired environmental variables was recommended for use in RIVPACS II. However, in view of the fact that several combinations of features showed little difference in predictive capability and there was pressure from the end-users for choice, a menu of 6 environmental options was finally offered in RIVPACS II (Table 2).

A notable new feature is the facility to select single or paired season predictions in addition to the original 3 season option available in RIVPACS I. If, for example, a biologist normally takes routine samples in spring and autumn or has to sample a site in summer after a pollution incident, then target predictions for spring and autumn combined or summer only can be obtained for comparison with the samples acquired on site.

RIVPACS II offers the same four taxonomic levels as RIVPACS I. They are:
(i) Species level
(ii) Family level
presence/absence

(iii) BMWP family level presence/absence + associated biological indices

(iv) Family level $\quad \log$ categories of abundance (ie $<10$ individuals per sample $=$ $\log$ cat. $1 ;<100=2 ;<1000=3$ etc).
Options (i)-(iii) are available for all combinations of seasons, but option (iv) is for single season predictions only.

In addition, a new facility is 'customization' of the taxonomic level at which the prediction is offered. This allows the user to downgrade the species level predictions to the taxonomic level used for a given purpose in their laboratory. This might involve all taxa taken to genus, or alternatively could be a mixture of family, genus and species identifications in different taxonomic groups, as specified by the user. In practice, several customizations can be defined and then called upon as and when the need arises.

One of the obvious limitations of RIVPACS I was the time required to input data to obtain a site classification or a prediction of the fauna. In RIVPACS II the facility to obtain one or more predictions by inputting data was retained but the option of retrieving environmental data for a series of sites from a computer file and running a series of predictions in batch mode was introduced to increase operational efficiency. A further option allows the storage of biological data for the same sites and automatic comparison of the observed fauna with the predicted (expected) fauna. This development, in which it becomes a simple matter to examine the ratio of observed fauna/expected fauna for any site, forms the basis of the biological site assessment. Examples of these options are demonstrated at species and BMWP family level in later sections.

The method used to classify new sites in RIVPACS II was also changed so that the full taxon listing obtained for the site after three seasons sampling was taken into ac-

TABLE 2. The six environmental options available for prediction in RIVPACS II

Eight variables used in all predictions:

$\begin{array}{ll}\text { Distance from source } & \text { Mean water width } \\ \text { Mean substratum } & \text { Mean water depth } \\ \text { Altitude } & \text { Latitude } \\ \text { Discharge category } & \text { Longitude }\end{array}$

Plus the following, according to option:

\begin{tabular}{lcccccc}
\hline Option & 1 & 2 & 3 & 4 & 5 & 6 \\
\hline Alkalinity & + & + & & + & + \\
Slope & + & & + & + & + \\
Mean air temperature & + & + & & + & + \\
Air temperature range & + & + & + & & + \\
Chloride & & & & & + \\
\hline
\end{tabular}


count. The taxon list was held in a computer file and a new technique (RUSHTON, 1987) involving the full taxon list was used to generate group membership probabilities for the site (see WRIGHT et al., 1993a, for more details).

All these developments took place around 1989 when there were major changes in the organisation of the Water Industry in England and Wales. Most of the biologists previously employed by the ten regional Water Authorities were transferred to a single new organisation, the National Rivers Authority (NRA) which had responsibility for monitoring water quality. It was therefore appropriate that the IFE team liaised closely with the NRA to ensure that RIVPACS II satisfied their requirements for the $1990 \mathrm{Ri}$ ver Quality Survey.

\section{A RIVPACS PREDICTION}

At this point it is appropriate to demonstrate the format in which a prediction appears, so that the method of comparing the observed with the expected fauna is clarified before some of the current uses of the system are examined.

The prediction which follows is at 'species' level, or more precisely at the highest taxonomic level available in the system, that is, the same level of identification as used in the original classification. It is in fact based on the 370 site classification system as used in RIVPACS I but uses one of a series of high quality sites which were later incorporated into RIVPACS II. These predictions were carried out on mainframe computer and incorporate the facility, later made available in RIVPACS II, of comparing the fauna actually observed at the site with the target prediction.

The site in question (Pinnocks Moor) is on the R. Crane/Moors River which is a tributary of the Dorset Stour in central southern England and has been scheduled as a grade 1 Site of Special Scientific Interest (SSSI) (RATCLIF$\mathrm{FE}$, 1977). Geologically the catchment is very diverse and the designation of sections of the river as an SSSI is predominantly due to the rich macrophyte communities and the occurrence of some scarce Odonata. Further information on the fauna is available in WRIGHT et al. (1988) and a recent paper (WRIGHT et al., 1993b) examines the value of RIVPACS I for identifying sites within the catchment which are either under stress or of high conservation value.

The format of the prediction is shown in Figure 3. The environmental data include a total of 11 physical and che- mical variables for prediction. (The four categories of substratum composition are combined to give mean substratum expressed in phi units). The three physical factors on the left hand side were recorded in each of three seasons (spring, summer and autumn) and the chemical data were annual mean values (minimum of three seasonal values, preferably more). These data, when used in MDA equations gave a series of probabilities of classification group membership. These were then converted into the listing of predicted taxa, given in decreasing probability of capture. This list forms the target assemblage to be expected after sampling in each of spring, summer and autumn using standard RIVPACS methodology.

Because this high quality site had been sampled in three seasons and the biological results were held in a computer file, it was possible to compare the target assemblage with the observed fauna and show, by means of an asterisk, which target invertebrates were actually found at the site. As previously explained, taxa predicted with almost $100 \%$ probability should, with few exceptions be present at an unstressed site, whereas 1 in 2 of the taxa predicted with a probability of $50 \%$ should be present after the standard sampling regime. In Figure 3, all taxa predicted with a probability above $50 \%$ are listed, but observed over expected ratios (O/E ratios) for the number of taxa are given at various stages in the prediction from $75 \%$ probability, through $50 \%$ to $25 \%$ to the final $\mathrm{O} / \mathrm{E}$ ratio at $0 \%$.

The ratio remains close to unity for much of the prediction $(75,50,25 \%)$ as would be expected at a good quality site, but the final $\mathrm{O} / \mathrm{E}$ ratio increased to 1.16 . This indicates that the site is taxon rich and supports a number of taxa which were predicted with a very low probability of occurrence by RIVPACS I. There are a number of possible explanations for this including the presence of a tributary on a contrasting subcatchment just upstream and the presence of an artificial lake alongside the river, both of which could contribute unexpected taxa.

\section{CURRENT USES OF THE SYSTEM:}

\section{a) River management}

For biologists involved in routine river management and the collection of data for periodic national surveys, the predictive capability of RIVPACS has been more useful than the classification option.

The first opportunity for widespread use of the system came in 1990 when RIVPACS II was made available to 
Environmental data used:

\begin{tabular}{|c|c|c|c|}
\hline Water width (m) & 4.2 & Altitude $(\mathrm{m})$ & 40 \\
\hline Mean depth $(\mathrm{cm})$ & 36.3 & Dist. from source $(\mathrm{km})$ & 8.2 \\
\hline Substratum composition & & Slope $\left(\mathrm{m} \mathrm{km}^{-1}\right)$ & 3.3 \\
\hline Boulders \& cobbles $(\%)$ & 1 & Air temp. range $\left({ }^{\circ} \mathrm{C}\right)$ & 12.51 \\
\hline Pebbles \& gravel $(\%)$ & 46 & Mean air temp. $\left({ }^{\circ} \mathrm{C}\right)$ & 10.55 \\
\hline Sand (\%) & 14 & Total oxidised $\mathrm{N}\left(\mathrm{mg} \mathrm{l}{ }^{-1} \mathrm{~N}\right)$ & 6.12 \\
\hline Silt \& clay (\%) & 39 & Alkalinity $\left(\mathrm{mg} \mathrm{l}^{-1} \mathrm{CaCO}_{3}\right)$ & 218.2 \\
\hline Mean substratum (phi) & 1.83 & Chlonde $\left(\mathrm{mg} \mathrm{l}^{-1} \mathrm{Cl}\right)$ & 13.9 \\
\hline
\end{tabular}

Groups predicted from MDA with 11 physical and chemical variables
$5143.3 \%$
$44 \quad 28.3 \%$
$104 \quad 12.4 \%$
$437.6 \%$
$1057.3 \%$

Predicted taxa, in decreasing order of probability:

* $98.1 \%$ Micropsectra/Tanytarsus

* $97.4 \%$ Glossiphonia complanata

* $96.9 \%$ Gammarus pulex

* $96.7 \%$ Hydracarina

* $94.6 \%$ Thienemannimyia gp

* $94.0 \%$ Orthocladius/Cricotopus

* 93.8\% Elmis aenea

* $93.1 \%$ Eukiefferiella sp.

* $93.0 \%$ Ceratopogonidae

90.6\% Pisidium subtruncatum

* $90.2 \%$ Ephemerella ignita

* $88.4 \%$ Erpobdella octoculata

* $86.9 \%$ Limnodrilus hoffmeisteri

* 86.3\% Baetis rhodani

* $86.2 \%$ Simulium (S) omatum

* $85.0 \%$ Potamopyrgus jenkinsi

$84.1 \%$ Hydroptila sp.

* $83.3 \%$ Pisidium nitidum

* $82.4 \%$ Baetis vemus

* $81.5 \%$ Psammoryctides barbatus

* $80.6 \%$ Stylodrilus heringianus

$80.5 \%$ Baetis scambus gp

* $80.0 \%$ Asellus aquaticus

* $77.7 \%$ Hydropsyche pellucidula

* $76.9 \%$ Polypedilum sp.

* $75.7 \%$ Ancylus fluviatilus

$74.6 \% \quad$ Helobdella stagnalis

* $72.6 \%$ Dicranota sp.
* $72.3 \%$

anytarsus/Paratanytarsu

$71.5 \%$ Lymnaea peregra

$70.3 \%$ Rhyacodrilus coccineus

$69.7 \%$

* $67.9 \%$

* $66.8 \%$

$66.6 \%$

* $65.5 \%$

* $65.1 \%$

* $64.8 \%$

* $64.3 \%$

$64.3 \%$
$64.2 \%$

- $64.1 \%$

$59.6 \%$

$58.1 \%$

* $57.3 \%$

* $56.0 \%$

* $55.4 \%$

* $55.2 \%$

* $53.6 \%$

* $53.6 \%$

* $53.0 \%$

$52.5 \%$

* $51.8 \%$

* $51.8 \%$

* $51.0 \%$

$50.4 \%$

$50.2 \%$
Prodiamesa olivacea

Aulodrilus pluriseta

Stylaria lacustris

Sphaerium corneum

Lumbnculus variegatus

Hydropsyche siltalai

Polycentropus flavomaculatus

Limnius volckmari

Microtendipes sp.

Rhyacophila dorsalis

Potthastia longimana gp

Caenis moesta gp

Halesus gp

Potamophylax gp

Lumbricidae

Limnephilus lunatus gp

Rheocricotopus sp.

Piscicola geometra

Orectochilus villosus

Athripsodes cinereus

Deronectes depressus gp

Sialis lutaria

Polycelis nigra gp

Centroptilum luteolum

Brychius elevatus
Probability

Observed no.taxa

Expected no.taxa
$75 \%$

$$
2 \frac{23}{22.74}=1.01
$$

$50 \%$

$4 \frac{42}{1.73}=1.01$
$25 \%$

$6 \frac{59}{1.16}=0.96$
$0 \%$

$\frac{92}{79.19}=1.16$

FIGURE 3. Demonstration of a "species" level prediction based on 11 environmental features for a site in southern England, using RIVPACS I. For further explanation see text.

each NRA region in England and Wales and to the RPBs in Scotland in time for the 1990 national River Quality Survey. This quinquennial survey always includes a chemical appraisal of quality based on a small number of determinands but biological assessments have not always been included. In 1980, a 'single season biological assess- ment using the BMWP system was undertaken at $2000 \mathrm{si}$ tes and although this produced a baseline data-set against which to record future change, it did not of itself give a reliable basis for determining biological site quality. Clearly, sites with few taxa and low BMWP scores were stressed, but for most other sites, the BMWP system by it- 
self gave no firm basis from which to judge whether the taxa actually present at a given site represented the fauna to be expected in the absence of environmental stress. This problem meant that biology was omitted from the 1985 survey, but by 1990 , with RIVPACS II available, there was a workable system in place for use on a national basis.

RIVPACS II uses information obtained at sites in Great Britain only, but the Department of the Environment (Northern Ireland) decided to use the same sampling methodology and apply RIVPACS II predictions on an experimental basis, therefore giving a uniform system for reporting throughout the UK. In all, a total of 8796 sites were examined during the survey (SWEETING et al., 1992) of which over 7000 were sampled in three seasons, whilst the remainder were sampled in just 1 or 2 seasons.

Prior to the 1990 survey, biologists had access to a video which showed the field procedures to be used in the biological assessment. All environmental data for the survey were input by a single NRA region and then printouts were validated by the appropriate region before predictions went ahead. Once all biological samples had been sorted at the individual laboratories, they were sent to the IFE where a subset of 700 samples were removed for resorting and the checking of identifications by IFE staff as an independent audit exercise.

All site assessments were made at BMWP family level and observed/expected ratios were calculated for BMWP score, number of taxa and ASPT. A major requirement for the national survey was to provide a simple statement of overall biological quality at sites throughout the country. Hence, a site banding system (A-D) was devised so that the location of good quality sites (A), moderate (B), poor (C) and very poor (D) sites and the river lengths to which the sampling sites related could be shown on maps. These provide a simple demonstration of the location of the major problem areas and hence the rivers needing immediate remedial action. This method of presentation has, of course, been used in several countries, but based on different biological methods. When it is repeated periodically using the same methodology it is an effective way of showing managers and politicians if progress is being made or whether new problems are emerging. The reduction of detailed RIVPACS predictions to simple bands does result in the loss of a large amount of information. However, it is important to remember that this detail is always available to the user when required for more thorough assessments at individual sites.
Banding divides a continuum from good to poor quality sites and it is difficult to devise a wholly scientific basis for the procedure. Our aim was to allocate unstressed sites to band $\mathrm{A}$ and those subject to progressively greater stress to bands B, C and D. It was also critical to ensure that those using the system were convinced that sites were being allocated to bands in a manner which would be relevant to them in river management. Hence, several options were devised and evaluated by NRA, RPB and DoE(NI) biologists before the system given below was accepted. Initially, bands were calculated for each of the $\mathrm{O} / \mathrm{E}$ ratios for BMWP score, number of taxa and ASPT based on 3 seasons's data as follows:

$\begin{array}{lccc}\text { Band } & \text { O/E } & \text { O/E } & \text { O/E } \\ & \text { BMWP } & \text { No.taxa } & \text { ASPT } \\ \text { A } & 20.75 & 20.79 & 20.89 \\ \text { B } & 0.50-0.74 & 0.58-0.78 & 0.77-0.88 \\ \text { C } & 0.25-0.49 & 0.37-0.57 & 0.66-0.76 \\ \text { D } & <0.25 & <0.37 & <0.66\end{array}$

Then, a single biological quality class for the site was obtained from the three individual bands using the following rule:

Final biological class to be the median of the three individual bands, except when the band for ASPT is lower, in which case, the final class conforms to the ASPT band.

\begin{tabular}{|c|c|c|c|c|}
\hline & $\begin{array}{c}\mathrm{O} / \mathrm{E} \\
\mathrm{BMWP}\end{array}$ & $\begin{array}{c}\mathrm{O} / \mathrm{E} \\
\text { No.taxa }\end{array}$ & $\begin{array}{c}\mathrm{O} / \mathrm{E} \\
\mathrm{ASPT}\end{array}$ & $\begin{array}{c}\text { Final site } \\
\text { class }\end{array}$ \\
\hline \multirow[t]{2}{*}{ Thus, } & B & $\mathrm{C}$ & A & B \\
\hline & $\mathrm{C}$ & $\mathrm{C}$ & A & $\mathrm{C}$ \\
\hline but & A & A & B & B \\
\hline
\end{tabular}

The mechanism for batch mode operation using RIVPACS II in the 1990 survey is shown in diagrammatic form below.

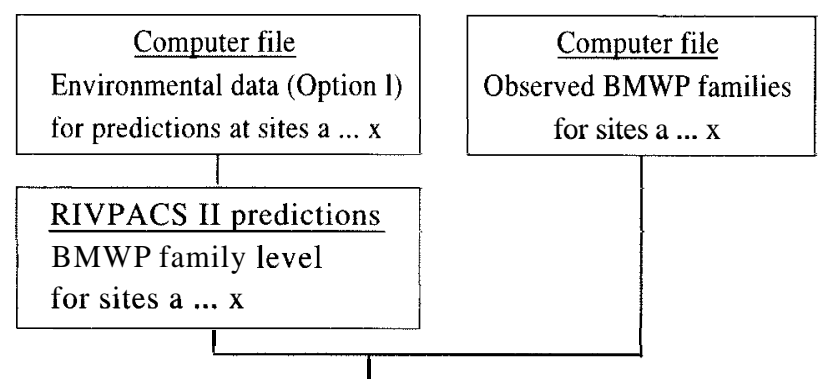

Automated comparison of observed and predicted (= expected) fauna and calculation of final biological banding 


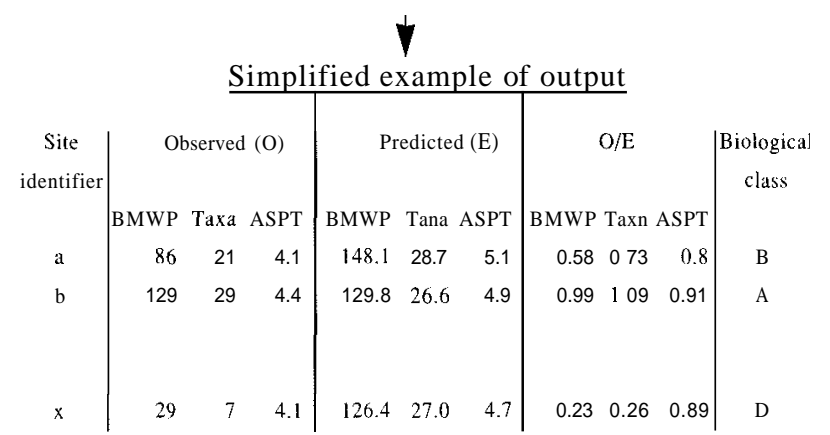

Use of the batch mode in RIVPACS II requires careful attention to the accuracy of both the environmental and biological data in the computer files before the predictions are run. However, once the data have been validated, a large number of predictions can be run overnight and the sites can be examined with respect to the final biological class the next morning.

Since the initial survey in 1990 , many regions have been repeating the survey at a large number of the routine monitoring sites. They have, therefore, been able to observe any class changes or the more subtle changes in $\mathrm{O} / \mathrm{E}$ ratios for individual biological indices. When more information is required, the listing of observed and expected BMWP families can be compared or further predictions can be made at species level using the same environmental data as for BMWP families. Where surveys are limited to 2 or just 1 season only, then different biological bands are required to those shown above for three season surveys. Based on the same rules as for 3 seasons, the band widths for two season surveys are only slightly wider than those for 3 seasons, but bands based on single season surveys are still wider. Hence if only single season sampling is possible at a site, the $\mathrm{O} / \mathrm{E}$ ratios need to be lower than for 2 or 3 seasons, in order to provide good evidence that a site is under environmental stress.

As catchment planning becomes more widely adopted and water quality objectives are set for individual river reaches, biological objectives can be set in terms of a stated biological class. If a section of river is currently achieving the required class, then it should be maintained, but if it is currently failing to meet its target, then plans can be made to reach the objective within a given timescale through investment to remove polluting influences.

RIVPACS II has also been used by the IFE in a number of Environmental Impact Assessments. These have involved, for example, a new road scheme where acid mine drainage was a problem (FURSE et al., 1990) and streams near Folkestone which were affected by works undertaken as part of the Channel Tunnel project (ARMITAGE, 1989).

\section{b) Conservation}

Although predictions which generate high $\mathrm{O} / \mathrm{E}$ ratios can be useful in confirming that sites are of good quality, other features of RIVPACS II and also the underlying data-base are of particular relevance in assessing conservation value.

Within Great Britain the system for scheduling Sites of Special Scientific Interest (SSSIs) is designed to produce a national series of flowing water sites which include high quality examples of all the major river types (BOON, 1991). During the early stages of this process the choice of rivers by the Nature Conservancy Council was made by consultation with experts coupled with a limited amount of survey work on the flora and fauna (RATCLIFFE, 1977). Later on, HOLMES $(1983,1989)$ developed a classification of river types based on aquatic and marginal vegetation which is now in widespread use by the present statutory nature conservation bodies. RIVPACS II also offers a method of site classification based on the macroinvertebrate assemblages and hence the latter offer a further check that all the major river types and zones, as reflected by their invertebrates, are included in the national series.

Use of objective procedures is becoming more important because scientific criteria and data are now required to demonstrate that current SSSIs are worthy of this status and that additional rivers are worth considering for future designation as SSSIs.

For a number of years the IFE has sampled good quality sites around Britain using standard RIVPACS methodology on behalf of the statutory nature conservation bodies. Therefore it has been possible to classify many SSSIs, and others which are under consideration for this status. In addition, as a result of the use of standard collection procedures, sites of interest can be placed in a national context with respect to their overall taxon richness, the richness of the component taxonomic groups and the occurrence of rare species.

Figure 4 is a simplified version of an output produced for the R. Monnow, a tributary of the R. Wye in South Wales. Four sites were sampled along the river and standard RIVPACS samples (three seasons) of the macroinvertebrate fauna were used to place the sites within the RIVPACS II classification. Next, the contribution of each major taxonomic group to total site richness is shown for 
each site and the latter is placed in the context of the mean richness for the classification group to which each site was assigned with the highest probability (ie site 1 was allocated to group $2 \mathrm{a}$ with $82 \%$ probability and the mean richness of 2a was 77; taxon richness actually recorded as 95 taxa). Finally, the presence of any Red Data Book (SHIRT, 1987) or nationally notable taxa either in the standard RIVPACS samples or in additional samples taken on behalf of the statutory nature conservation bodies are recorded and notes appended. In a full report, the list of 200 taxa recorded during the survey would be given by site, season of capture and whether recorded in RIVPACS samples or during additional sampling.

This approach allows those evaluating sites to compare equivalent data for a wide range of rivers. It is therefore possible to present an objective case for the protection of a particular river on the basis of high taxon richness or the occurrence of rare species. An example of the use of RIV$\mathrm{PACS}$ to locate taxon-rich sites by their high $\mathrm{O} / \mathrm{E}$ ratios and the value of the underlying data-set to identify taxa which are infrequent in running-water sites can be found in WRIGHT eral. (1993b).

A new initiative (BOON, in press) termed SERCON System for Evaluating Rivers for Conservation is currently under development in Great Britain to help in assessing the conservation value of rivers. Some of the options in RIVPACS II which are relevant to conservation are likely to be of value as input to the overall river evaluation being developed as SERCON.

\section{FURTHER APPLICATIONSOF THE SPECIES DATA:}

\section{a) Species distribution}

As a result of the large number of sites examined in Great Britain and the effort expended in identification, species new to Britain have been discovered and our knowledge of the distribution of infrequent taxa has been extended. Species not previously recorded in Great Britain include a non-biting midge (Chironomidae) in Scotland (FURSE et al., 1984) and two species of Oligochaeta in southern England.

Information on the frequency of occurrence of each taxon in the sites used in RIVPACS is a unique source of information on the occurrence of macroinvertebrates in rivers throughout the country. Our surveys have provided more information on the status of both Red Data Book and nationally notable species whilst producing new data on infrequent and little-studied groups of macroinvertebrates. For common species, the production of $10 \mathrm{~km}$ square dot maps showing presence-absence data can also be informative.

Future examination of the distribution of a species and the environmental attributes of the sites at which it occurs offer interesting possibilities for the exploration of environmental ranges and for comparisons between related species.

\section{b) Invertebrate assemblages}

The species richness of the macroinvertebrate fauna varied considerably between sites and is illustrated in Figure 5 for the 370 sites in RIVPACS I. At $226(61 \%)$ of these sites between 60 and 90 taxa were recorded, but the full range was 34-136. Sites with fewer than 60 taxa were typical of upland parts of Scotland, Wales and England where conditions were physically severe. In contrast, a wide variety of locations supported $>90$ taxa and the most species-rich sites encompassed both upland and lowland locations in England and Wales. They included fast-flowing rivers in mid and south Wales, small streams in the southwest of England, the chalk streams of southern England and finally more sluggish lowland systems in East Anglia. All these species-rich river types had distinctly different assemblages of macroinvertebrates.

The full complement of taxa used in developing RIVPACS I included 144 non-insect and 431 insect taxa, making a total of 575 . The number of taxa in each major taxonomic group is shown in Table 3 . When the 30 classification groups in RIVPACS I are examined as a whole, one of the most obvious features which distinguishes the fauna of upland from lowland classification groups is the contribution of insects to the species pool. Figure 6 displays the TWINSPAN groups in the sequence in which they were listed after analysis, which is essentially from upland to lowland. The number of insect taxa are expressed as a percentage of the total macroinvertebrate taxa recorded at the sites which comprise each group. It is apparent that insect taxa dominate the fauna of upland systems. This figure offers a clear illustration of a common observation, which is believed to have its origin in the colonization of freshwaters from the sea, in the case of non-insects, and from the land by insects.

An examination of correlations between a small selection of site environmental attributes is also instructive 
A. Site classification using standardised RIVPACS samples

$\begin{array}{llll} & \text { Site name } & \text { Grid ref. } & \text { Site classification } \\ \text { 1. } & \text { Llanveynoe } & \text { S0309318 } & \text { 2a }(82 \%) 1(10 \%) \\ \text { 2. } & \text { Clodock } & \text { S0327278 } & \text { 3a }(61 \%) 2 \mathrm{a}(25 \%) 5 \mathrm{a}(11 \%) \\ \text { 3. } & \text { Great Goytre } & \mathrm{S} 0365245 & 3 \mathrm{a}(57 \%) 5 \mathrm{a}(38 \%) \\ \text { 4. } & \text { Rockfield } & \mathrm{S} 0483153 & 7 \mathrm{~b}(32 \%) 4 \mathrm{c}(27 \%) 4 \mathrm{~b}(27 \%)\end{array}$

B. Taxon nchness using standardised RIVPACS samples

\begin{tabular}{|l|r|r|r|r||}
\hline \multirow{2}{*}{ Taxonomic group } & \multicolumn{4}{|c|}{ No. taxa per site } \\
\cline { 2 - 5 } & 1 & 2 & 3 & 4 \\
\hline Tncladida & 2 & 1 & 2 & 2 \\
Gastropoda & 4 & 3 & 2 & 5 \\
Bivalvia & $\mathbf{3}$ & $\mathbf{2}$ & 3 & 5 \\
Oligochaeta & 9 & 6 & 13 & $\mathbf{1 0}$ \\
Hirudinea & 2 & & 4 & \\
Hydracanna & 1 & & 1 & \\
Crustacea & 1 & 2 & 2 & 1 \\
Epherneroptera & 12 & 12 & 16 & 13 \\
Plecoptera & 1 & 2 & 7 & 3 \\
Hemiptera & 1 & 1 & 1 & 4 \\
Coleoptera & 8 & 9 & 8 & 8 \\
Megaioptera & & & 1 & \\
Trichoptera & 11 & 12 & 16 & 11 \\
Diptera & 29 & 33 & 36 & 26 \\
\hline Site taxon richness & 95 & $\mathbf{8 9}$ & 112 & $\mathbf{8 8}$ \\
\hline Mean richness for & 77 & 79 & $\mathbf{7 9}$ & 90 \\
classification group & & & & \\
\hline
\end{tabular}

C. Threatened and rare taxa in the RIVPACS and/or additional samples

$\begin{array}{llll}\text { Coleoptera } & \text { Hydraena rufipes } & \text { Notable } & 1,2 \\ & \text { Normandia nitens } & \text { RDB 2 } & 4 \\ & \text { Oulimnius troglodytes } & \text { Notable } & 4 \\ & \text { Riolus cupreus } & \text { Notable } & 4 \\ & \text { Riolus subviolaceus } & \text { Notable } & 4 \\ \text { Megaloptera } & \text { Sialis nigripes } & \text { Notable } & 2,3 \\ \text { Diptera } & \text { Atrichops crassipes } & \text { RDB 3 } & 4\end{array}$

The elmid beetle, Normandia nitens, has a restricted distribution and Shirt (1987) only gives confirmed modern records for the R. Wye and R. Teme.

The athericid, Atrichops crassipes, has a very distinctive larva and is also known from the R. Wye and a srnail number of sites in England (IFE records).

FIGURE 4. Example of a summary statement on the macroinvertebrate fauna of four sites on the R. Monnow, a tributary of the R. Wye in Wales

(Table 4), although rnany of the environmental factors are interrelated. On a geographical scale, it is apparent that species richness decreases from south to north within Great Britain. Topographical features also play a role and sites at high altitudes or on steep slopes tend to exhibit lower species richness. Featurcs which relate to locations along a water course (distance downstream, width, depth) suggest a very marginal increase in richness downstream in what are essentially small rivers on a European scale. The positive correlation with mean substraturn also indicates higher richness on fine as opposed to coarse substrata. All the chemical factors listed demonstrate that there is 


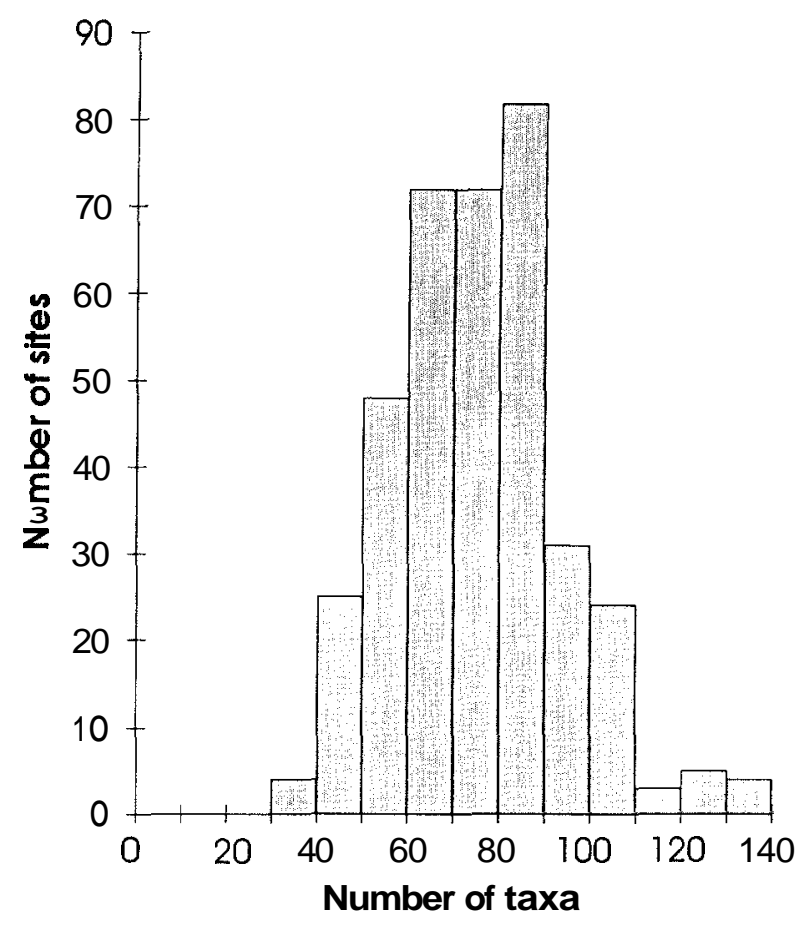

FIGURE 5. Macroinvertebrate taxon richness at the 370 sites in RIVPACS I.

a positive relationship between the mineral content of the water and species richness. Finally, with an increase in the mean percentage cover of macrophytes there is a tendency for a richer assemblage of macroinvertebrates to occur. These results can only offer a superficial first view and clearly, different taxonomic groups will respond in mar- kedly different ways to particular environmental features.

As a demonstration of this, we can investigate the response of different taxa to a range of environmental conditions. When macroinvertebrate data for the 370 sites were ordinated using DECORANA, the first axis strongly correlated with substratum type and also with alkalinity. Essentially the upland rivers were being distinguished from lowland types. The second axis was strongly correlated with distance downstream, in other words the species assemblages were undergoing progressive change downstream even though the overall species richness was relatively stable (Table 4).

By taking the 370 site data-set and partitioning the sites into five dominant substratum categories (from coarse to fine) and also into five distance categories downstream, it was possible to calculate the frequency of occurrence of various taxonomic groups under different environmental conditions.

Figure 7 brings together information on four different families with contrasting feeding requirements and distribution patterns. Stoneflies in the family Chloroperlidae are represented by just two species of predators, both of which are typical of upland streams with a coarse substratum. In contrast, mayflies in the family Heptageniidae are represented by a wider range of species which are predominantly grazer/scrapers. They have a greater tendency to occur downstream than the Chloroperlidae and also a greater capacity to exploit streams with a less coarse substratum of pebbles and gravel. Predatory leeches in the family Glossiphoniidae have a high frequency of occurrence in

TABLE 3. Number ofdifferent taxa found at the 370 sites in RIVPACS I ( ${ }^{*}$ taxa not identified beyond major group)

\begin{tabular}{lrlr}
\hline \hline Non-Insect Taxa & & Insect Taxa \\
\hline${ }^{*}$ Spongillidae & 1 & Ephemeroptera & 34 \\
${ }^{*}$ Hydridae & 1 & Plecoptera & 26 \\
Tricladida & 9 & Odonata & 12 \\
${ }^{*}$ Chordodidae & 1 & Hemiptera & 22 \\
${ }^{*}$ Bryozoa & 1 & Coleoptera & 84 \\
Gastropoda & 29 & Megaloptera & 3 \\
Bivalvia & 20 & Neuroptera & 2 \\
Oligochaeta & 53 & Trichoptera & 27 \\
Hirudinea & 14 & Lepidoptera & 159 \\
Hydracarina & 1 & Diptera & \\
Crustacea & 14 & & 431 \\
\hline Total & 144 & Total & \\
\hline
\end{tabular}


TABLE 4. Correlation coefficients between selected site features and macroinvertebrate species nchness. Variables with an astensk $\left({ }^{*}\right)$ were $\log _{10}$ transformed $(\mathrm{n}=370)$.

\begin{tabular}{|c|c|}
\hline Environmental Variable & $\mathrm{r}$ \\
\hline Latitude & -0.426 \\
\hline Longitude & O. 130 \\
\hline * Slope $\left(\mathrm{m} \mathrm{km}^{1}\right)$ & -0.300 \\
\hline * Altitude (m) & -0.307 \\
\hline${ }^{*}$ Distance from source $(\mathrm{km})$ & 0.137 \\
\hline${ }^{\star}$ Mean width $(\mathrm{m})$ & 0.062 \\
\hline * Mean depth $(\mathrm{cm})$ & O.109 \\
\hline Mean substratum (phi) & 0.268 \\
\hline $\mathrm{pH}$ & 0.144 \\
\hline${ }^{*}$ Total oxidized nitrogen $\left(\mathrm{mg} \mathrm{l}^{-1} \mathrm{~N}\right)$ & 0.269 \\
\hline${ }^{\star}$ Chloride $\left(\operatorname{mg~} 1^{\mathrm{l}} \mathrm{Cl}\right)$ & 0.119 \\
\hline Total Alkalinity $\left(\mathrm{mg}^{1} \mathrm{CaCo}_{3}\right)$ & 0.174 \\
\hline Mean macrophyte cover (\%) & 0.181 \\
\hline
\end{tabular}

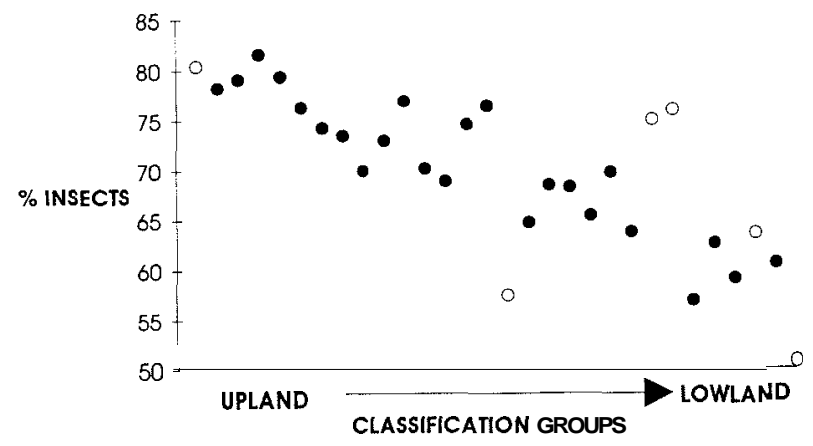

FIGURE 6. Changes in the proportion of insect taxa in the 30 classification groups of RIVPACS I from upland to lowland groups. Open circles represent very small groups with 1 or 2 sites only.

lowland and intermediate streams but are less frequent at sites with a very coarse substratum, particularly in small streams. Deposit-feeding gastropods in the family Valvatidae are more strongly associated with finer substrata and tend to occur with greater frequency downstream.

These examples are rather simplistic demonstrations of the type of information available, and in future we plan to develop a flexible data-base incorporating both the biological and environmental data for more detailed analyses.

\section{FUTURE DEVELOPMENTS}

Development of RIVPACS has been a long process in which, at various stages. we have made technical advan- ces, discovered some inadequacies in the system and sought to rectify them. Further development work is currently underway to ensure that a new version, RIVPACS III is available in time for the 1995 River Quality Survey.

The use and testing of RIVPACS 11 during the 1990 survey was a valuable means of judging the strengths, but also the weaknesses of the system based on 438 sites. The IFE was also asked to undertake an extensive series of tests in order to pinpoint those areas in need of attention before the 1995 Survey. The general assessment was that, overall, the system was performing reasonably well, but that there were some problems which needed attention if the technique was to be universally acceptable within the UK.

It was apparent that some river types were not being predicted satisfactorily simply because the data-base lacked suitable examples of sites on which to draw in making the prediction. This was particularly apparent in parts of Scotland where the density of sites was lower than elsewhere. There was also a need to include good quality sites from Northern Ireland to make the system relevant to the whole of the UK. Hence, the data-base for RIVPACS III will be increased to 700 high quality sites. This will be achieved by using currently available data from a range of good quality sites previously collected for the Nature Conservancy Council and its successor organisations and also by incorporating further sites recommended by biologists from the NRA, RPBs and the DoE (NI).

Predictions for one very characteristic river type were found to be less than optimal because of the way the original classification had failed to draw together sites of this type. Here was a demonstration of the limitations of the classification and prediction system itself. This example, together with further points relating to the method of prediction indicated that there could be value in exploring alternative methods of classification and prediction prior to the development of RIVPACS III. Given the many alternative methods of classification now available, we are making some comparisons between the continued use of TWINSPAN and the benefits, or otherwise, of a range of other techniques.

In addition, as the need increases to provide reliable assessments of the biological condition of sites, further efforts are being made to increase the robustness of the system to ensure that it meets the operational requirements of users.

In conclusion, one can ask whether our approach is relevant to other countries in Europe, and in the present 


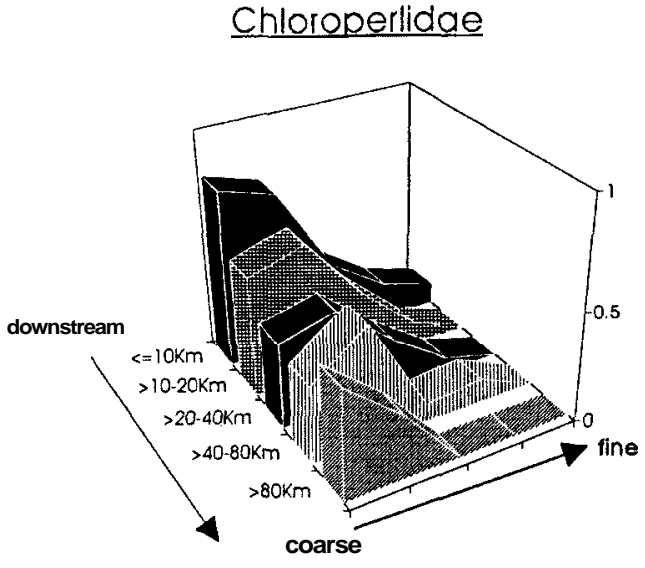

Heptageniidae

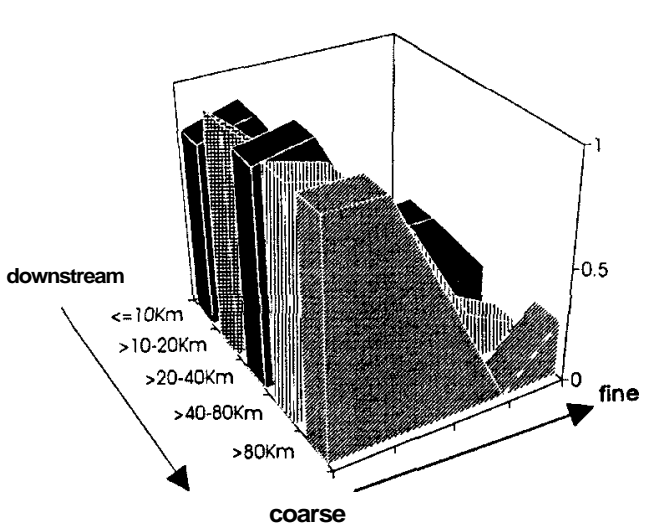

Glossiphoniidae

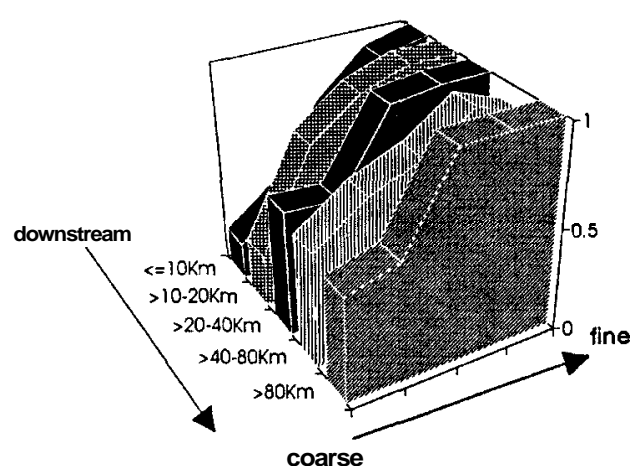

Valvatidae

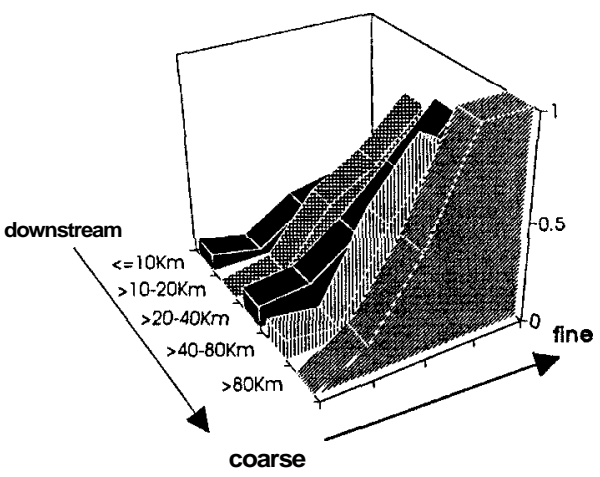

FIGURE 7. Frequency of occurrence (scale 0-1) of selected families in relation to location downstream and substratum type based on 370 sites. See text for further details

context to Spain. The basic methodology has been in the scientific literature for some years and a number of scientists within Spain have already expressed interest in the technique. In fact, demonstration predictions based on just five environmental variables from RIVPACS I were recently attempted at BMWP family level on two rivers in N.W. Spain with some success (ARMITAGE et al., 1990). However, Britain has a restricted range of families of macroinvertebrates compared to Spain and there are very substantial differences in the fauna at species level. Hence the faunal and also the environmental database which has been developed for rivers in the UK can never have direct application to the full range of environmental conditions and macroinvertebrate assemblages within Spain.

The question must therefore be asked: - what is required to undertake the development of a similar system in one or more regions of Spain? Clearly, it is essential to have a wide variety of good quality rivers to act as refe- rente sites. Appropriate sampling regimes must then be devised and a uniform level of identification must be adopted for inter-site comparisons. There is also a need for good quality environmental data from which to develop the prediction system. In addition to these general considerations, there are further points best resolved by experts within Spain.

First, Spain is a remarkably diverse country with a wide range of macroinvertebrate assemblages (ALBA-TERCEDOR et al., 1992). It may be appropriate to divide the country into a series of biogeographical regions prior to undertaking studies on one or more regions separately. Second, despite the enormous progress made in documenting the macroinvertebrate fauna of rivers in Spain during the 1980 s, much still remains to be done because the fauna is very rich and also because of the numerous endemic species within the Iberian Peninsula (ALBA-TERCEDOR et a1., 1992). 
Therefore, if there were to be sufficient interest within Spain to develop a pilot version of RIVPACS using faunal and environmental data for a defined region, the level to which the fauna was identified (species, genus, family) would be a critical decision. This decision would affect the cost of developing the system, the reliability of the predictions and the range of applications for the results. It would be wise to retain all specimens so that further identifications could be undertaken if required and to allow for the rechecking of specimens in the light of experience.

Finally, it will be apparent that we have enjoyed a longterm commitment from our funding agencies in order to develop RIVPACS. We believe that the system has a valuable part to play in both river management and in the conservation of the fauna in the UK. The original data for each site also provides an unrivalled record of the macroinvertebrate fauna for future reference.

\section{ACKNOWLEDGEMENTS}

The research described in this manuscript is the result of a team-effort and I would like to acknowledge the dedication of the whole team and in particular my senior colleagues, Dr P.D. Armitage, Mr M.T. Furse and Dr D. Moss for the success of the project. Funding for the early stages of the work came from the Natural Environment Research Council (NERC) and the Department of the Environment, together with the Welsh Office and Scottish Development Department. More recently, new developments have been possible through the support of the National Rivers Authority, the Scottish Office Environment Department and the Department of the Environment (Northern Ireland). The NERC funded the writing of this manuscript.

I would also like to thank the Organizing Committee of the VII Congress of the Spanish Association of Limnology for inviting me to present our work at the Congress held in Bilbao in June 1993.

\section{REFERENCES}

ALBA-TERCEDOR, J., G. GONZALEZ \& M.A. PUIG, 1992. Present level of knowledge regarding the fluvial macroinvertebrate communities in Spain. Limnética 8: 231-241.

ARMITAGE, P.D., D. MOSS, J.F. WRIGHT \& M.T. FURSE, 1983. The performance of a new biological water quality score system based on macroinvertebrates over a wide range of unpolluted running-water sites. Water Rese- arch 17: 333-347.

ARMITAGE, P.D., 1989. Channel Tunnel. NERC News 8: 9.

ARMITAGE, P.D., I. PARDO, M.T. FURSE \& J.F. WRIGHT, 1990. Assessment and prediction of biological quality. A demonstration of a British macroinvertebratebased method in two Spanish rivers. Limnética 6: 147 156.

ARMITAGE, P.D., M.T. FURSE \& J.F. WRIGHT, 1992. Anexo: Calidad medioambiental y valoración Biológica en los ríos británicos. Perspectivas de pasado y futuro. In: Viceconsejería de Medio Ambiente del Gobierno Vasco y ANA RALLO (ed.): Caracterización Hidrobiológica de la red fluvial de Alava y Gipuzkoa: 477-511. Itxaropena, S.A. Zarautz.

BOON, P.J. 1991. The role of Sites of Special Scientific Interest (SSSIs) in the conservation of British rivers. Freshwater Forum 1 (2): 95-108.

BOON, P.J. (in press) An expert system for evaluating rivers for conservation ("SERCON"). An outline of the underlying principles. Verh. Intenat. Verein. Limnol.

CHANDLER, J.R. 1970. A biological approach to water quality management. Wat. Pollut. Control, Lond. 69: 415 422.

DEPARTMENT OF THE ENVIRONMENT AND THE WELSH OFFICE, 1986. River Quality in England and Wales 1985. A report of the 1985 Survey. HMSO, London. $42 \mathrm{pp}$.

FURSE, M.T., P.D. ARMITAGE \& J.F. WRIGHT, 1984. Parametriocnemus boreoalpinus Gowin (Diptera: Chironomidae) new to Britain, with notes on the separation of larvae and pupae of the British species. Entomologist's Gazette 35: 265-269.

FURSE, M.T., J.N. FERNANDES, J.F. WRIGHT \& P.D. ARMITAGE, 1990. The use of aquatic macroinvertebrate assemblages for assessment of the environmental quality of rivers. In: River Water Quality, assessment and management. Proceedings of an International Seminar, Lisbon 17-19 May 1990. UNESCO; 171-181.

GAUCH, H.G. \& R.H. WHITTAKER, 1981. Hierarchical classification of community data. Journal of Ecology 69: 537-557.

HELLAWELL, J.M. 1986. Biological Indicators of freshwater pollution and environmental management. Elsevier Applied Science, London and New York. 546 pp.

HILL, M.O. 1979. TWINSPAN - A FORTRAN program for arranging multivariate data in an ordered two-way table by classification of the individuals and the attributes. Ecology \& Systematics, Cornell University, Ithaca, N.Y. 90 pp. 
HOLMES, N.T.H. 1983. Typing British rivers according to their flora. Focus on Nature Conservation No. 4. Nature Conservancy Council.

HOLMES, N.T.H. 1989. British rivers. A working classification. British Wildlife 1: 20-36.

KLECKA, W.R. 1975. Discriminant analysis. In: SPSS Statistical Package for Social Sciences. N.H. Nie, C.H. Hull, J.G. Jenkins, K. Steinbrenner and D.H. Bent. McGraw-Hill, New York. 434-467.

MOSS, D., M.T. FURSE, J.F. WRIGHT \& P.D. ARMITAGE, 1987. The prediction of the macroinvertebrate fauna of unpolluted running-water sites in Great Britain using environmental data. Freshwater Biol. 17: 41-52.

NATIONAL WATER COUNCIL 1981. River quality: the 1980 survey and future outlook. National Water Council.

RATCLIFFE, D.A. (ed.) 1977. A nature conservation review. Cambridge University Press. 1: 1-401 and 2: 1320.

RUSHTON, S.P. 1987. A multivariate approach to the assessment of terrestrial sites for conservation. In: The use of invertehrates in site assessment for conservation. Proceedings of a meeting held at the University of Newcastle-upon-Tyne, 7 January 1987. M.L. LUFF (ed.) Agricultural Environment Research Group, University of Newcastle-upon-Tyne.

SHIRT, D.B. (ed.) 1987. British Red Data Books: 2. Insects. Peterborough, Nature Conservancy Council.

SWEETING, R.A., D. LOWSON, P. HALE \& J.F. WRIGHT, 1990. Biological assessment of rivers in the UK. In: River Water Quality - Ecological Assessment and Control. P.J. NEWMAN, M.A. PIAVAUX \& R.A. SWEETING, eds. CEC Brussels, 319-326.
VERNEAUX. J. 1976. Fondements biologiques et écologies de l'étude de la qualité des eaux continentales Principales méthodes hiologiques. In: La Pollution des Eaux Continentales. Incidence sur les Biocenoses aquatiques. P. PESSON ed. GauthierVillars, Paris, 229-285.

WOODIWISS, F.S. 1964. The biological system of stream classification used by the Trent River Board. Che mistry \& Industry $11: 443-447$

WRIGHT, J.F., D. MOSS, P.D. ARMITAGE \& M.T. FURSE, 1984. A preliminary classification of running-water sites in Great Britain based on macroinvertebrate species and the prediction of community type using environmental data. Freshwat. Biol 14: 221-256.

WRIGHT, J.F., P.D. ARMITAGE, M.T. FURSE \& D. MOSS, 1988. A new approach to the biological surveillance of river quality using macroinvertebrates. Verh. Internar. Verein. Linztzol. 23: 1548-1552.

WRIGHT, J.F., J.S. WELTON, M.T. FURSE \& R.J.M. GUNN. 1988. The macroinvertebrate fauna of the Moors River and Uddens Water in Dorset. Proc. Dorset Nat. Hist. \& Arch. Soc. 110: 127-135.

WRIGHT, J.F., M.T. FURSE, \& P.D. ARMITAGE (1993a). RIVPACS - a technique for evaluating the biological quality of rivers in the U.K. European Water Pollution Control 3 (4): 15-25.

WRIGHT, J.F., M.T. FURSE, P.D. ARMITAGE \& D. MOSS (1993b). New procedures for identifying runningwater sites subject to environmental stress and for evaluating sites for conservation, based on the macroinvertebrate fauna. Arch. Hydrohiol. 127: 319-326. 